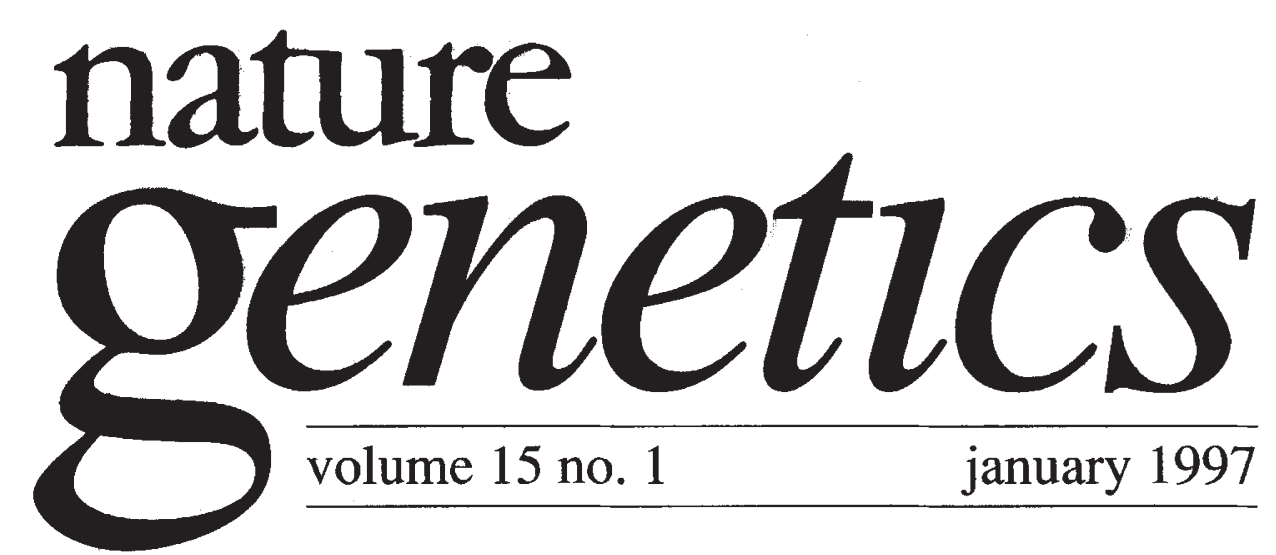

\title{
Brave new now
}

Eugenics - the word evokes dramatic images of Huxley's battery babies, of Hitler's Aryan fantasies, of policies that were in force in another country or distanced by time. Eugenicist philosophy has informed public law and policy - in both the East and the West - over the past century and is likely to assume greater significance with the dramatic advances in genetic technology and the dual challenge of global population growth and dwindling environmental resources.

Francis Galton defined and named 'eugenics' in 1883 and debated with his cousin, Charles Darwin, and Alfred Russel Wallace the possibility that selective breeding might affect population phenotype or whether such adventures were futile, irrelevant and likely to distract attention from necessary social reform. Many countries subsequently sought answers to these questions by enacting laws designed to either segregate or to eliminate the 'unfit'. Earlier this century, 30 states in North America enacted eugenic laws that included directives for compulsory sterilization, leading to over 60,000 legal sterilizations, many of which were carried out on individuals tenuously diagnosed as 'feeble-minded'l. In Alberta, Canada, more than 2,500 people were legally sterilized up to 1972 - including (already) sterile boys with Down syndrome, illiterate immigrants and delinquents ${ }^{2}$. And of course there are the Nazi atrocities, the nadir of eugenic practice. In many settings, the eugenics 'movement' has enjoyed support and endorsement from scientific, political and philanthropic bodies.

In contrast with the crude examples cited, the stated intention of much genetic research is eugenicist by implication. Implicit in every research grant written for the study of a genetic disorder is the suggestion that the disorder may be corrected or that identification of a 'causative' gene or genes will help in population screening or fetal diagnosis. Although there has been considerable debate on issues of reproductive technology, screening for the detection of serious genetic disease seems to be widely accepted in Western societies.

IMAGE UNAVAILABLE FOR COPYRIGHT REASONS This may not always be the case. Recent events give testimony to public concern that genetic information may be used (or is being used) to discriminate against individuals. A recent case in which the U.S. army was challenged over its mandatory DNA collection programme $^{3}$ represents a potential conflict of interest between government and employee over genetic material. The Kennedy-Kassebaum law $^{4}$ in the United States and numerous debates and articles (see page 16 for example) $)^{5}$ indicate that the 'ownership' of genetic knowledge can be a powerful commodity, not only for geneticists 
1. Paul, D.B. Controlling Human Heredity: 1865 to the Present (Humanities Press, New Jersey, 1995).

2. The Economist, 16 November, $48-49$ (1996)

3. Lehrman, S. Nature, 379, 385 (1996).

4. Smith, O. Nature Med, 2, 613 (1996).

5. Boshar, M., Nature Genet. 15, 16-20 (1997).

6. The Maternal and Infant Health Care Law, Order of the President of the People's Republic of China, No. 33, 27 October 1994.

7. Articles 3 and 5 . Rules of the Standing Committee of the Gansu People's Congress Prohibiting Feeble-Minded Persons From Having Children, 23 Persons From Having Children, 23
November, 1988, People's Republic of November, 1988, People's Republic of
China.

8. Articles 8 and 10. Liaoning Province Regulations on the Prevention of Inferior Births, 13 January, 1990, People's Republi of China.

9. Dickson, D. Nature 367, 3 (1994).

\section{Correction}

In November's editorial, the author of the 'The Eighth Day of Creation' was incorrectly cited. It was in fact Horace Freeland Judson who wrote the book. but also for insurance companies, the legal profession and, indeed, the state.

A law ${ }^{6}$ enacted in the People's Republic of China 18 months ago has sparked furious debate on the manner in which it is appropriate for scientists of one culture or country to criticize the way in which genetic information is used to inform the law of another. Its original bill, 'the Eugenics and Health Care Protection Law' was drafted in 1993 by the Ministry of Public Health. On advice from individuals in the international community and as a consequence of some discontent within the health ministry itself, a revised bill was drafted. In fact, variations of this law have been in effect since 1989 and 1990 in the provinces of Gansu ${ }^{7}$ and Liaoning ${ }^{8}$ respectively, where regulations entailed mandatory sterilization and abortion in specified cases. In Liaoning, these included degeneration of the retina and 'autosomal recessive inherited disease on one side [of a couple]' (emphasis added).

Under Article 10 of China's new Maternal and Infant Health Care Law (MIHCL), people diagnosed with a 'genetic disease of a serious nature' are asked to take (unspecified) long-term contraceptive measures or to be sterilized. Article 16 is less specific, although it implies compulsory prenatal testing and pressure on women to abort under certain circumstances. The law also states that any abortion or sterilization must be agreed by the person concerned, although 'if the person has no capacity for civil conduct', permission of a guardian is considered sufficient. It forbids the prenatal revelation of fetal sex unless medically relevant and has deep roots in China's population control policy. Population growth and the control of disease are global problems; with more than a fifth of the world's population, China does well to take them seriously and its way of so doing reflects a different cultural ethic from that of most Western countries. Articles 10 and 16 of the MIHCL, however, will not help. The nature of recessive mutation precludes significant impact on the incidence of serious genetic disease. Moreover, the genetic control of mental disorders is ill-defined, and application of the law is likely to obscure the environmental causes of certain disorders, both mental and physical. Finally, the law may well provide cover for abuse, as did similar laws in North America and Canada. The observations of Chen Minzhang, the Minister of Public Health, are not reassuring: apparently births of 'inferior quality' are serious among 'the old revolutionary base, ethnic minorities, the frontier and economically poor areas'.

The next International Congress of Genetics is due to take place in Beijing in 1998 (see page 15). Last November, the British Genetical Society voted to suspend its affiliation with the International Genetics Federation (IGF) in protest at the proposed venue and because of the MIHCL. Encouraged by Chinese colleagues, an international panel of geneticists signed a declaration protesting the law at the American Society for Human Genetics (ASHG) meeting in October. An ASHG business meeting convened at the same time ended in heated debate although the final resolution supported the prospective Congress. Unfortunately, the IGF has dedicated only one seminar (out of about 50) to the discussion of population genetics that, according to its organiser and contrary to earlier reports, will not explicity underscore eugenics or the MIHCL. There appears to be some tension between the Chinese authorities and the organisers of the Congress regarding the content of the symposium.

The British boycott is perceived by some to be a political hijacking of an event designed to foster apolitical scientific exchange across international borders. Indeed, any obstacle in communication between members of the international community is tragic. However, in the face of eugenic law, the genetical is political. China has a strong interest in genomics as evidenced by the recent deal with the French company, Genset, and it is thought that other countries with an interest in eugenic law will take note of events. Ideally, the congress in Beijing should act as a platform for international debate and as a venue for unrestricted and explicit discussion of eugenics and genetics. Should it transpire that communication is likely to be restricted, a boycott would serve as a vehicle to raise the profile of this global issue, to provoke discussion and debate, and to register a vote of concern. 